\title{
Inovação Organizacional para o Consumo Sustentável: A Inserção de Novas Práticas e Tecnologias nos Negócios do Walmart Brasil ${ }^{1}$
}

\author{
Organizational Innovation for Sustainable Consumption: The \\ Introduction of New Technologies and Business Practices of the \\ Walmart Brazil
}

\author{
Minelle Enéas da Silva \\ Doutorando em Administração pela Universidade Federal do Rio Grande do Sul - UFRGS \\ Mestre em Administração pela Universidade Federal de Pernambuco - UFPE \\ Professor da Universidade Federal do Rio Grande do Sul \\ Endereço: Rua General Lima e Silva, 30 - Centro - Porto Alegre-RS. \\ CEP: CEP: 90.050-100, e-mail: minele.adm@gmail.com
}

\begin{abstract}
RESUMO
O objetivo do presente artigo é identificar quais e como a inovação organizacional vem sendo inserida nas práticas do Walmart Brasil, a partir do desenvolvimento de práticas e tecnologias direcionadas para o padrão de consumo sustentável (CS). Com essa visão, diferentes ações e práticas devem existir para uma melhor atuação empresarial. Com pesquisa exploratória e abordagem qualitativa, o estudo de caso com a marca Hiper Bompreço, indica que poucas são as inovações efetivadas no contexto estudado, o que difere da prática nacional que busca inovações sustentáveis que contribuam com a estratégia da empresa. Dentre as práticas que foram identificadas, percebe-se que como indicaram Silva, Corrêa e Gómez (2012), as inovações voltadas para o CS são desenvolvidas em diferentes áreas, o que pode sugerir uma atuação mais responsável da empresa. Com isso, percebe-se que de todos os processos de gestão, a partir de inovação organizacional, que podem ser visualizados (gestão da água, de emergia, de resíduos e de transporte), apenas o de transporte não possui nenhuma influência no contexto da marca analisada. Todas as demais estão em processo de criação de ações que consigam estimular novas práticas organizacionais.
\end{abstract}

Palavras-chave: Inovação Organizacional. Consumo Sustentável. Varejo.

\section{ABSTRACT}

The purpose of this article is to identify which and how organizational innovation has been inserted in the practices of WalMart Brazil, from the development of practices and technologies aims at sustainable consumption (SC) patterns. According to this view, different actions and practices can exist for better business performance. With exploratory character and qualitative approach, the case study with the brand Hiper Bompreco, indicates that there are few innovations studied in the context, which differs in relation to the national actions, wich sustainable innovations can contribute with the company's strategy. Among the practices that have been identified, it is clear that innovations aiming the SC are developed in different business activities, which can suggest a more responsible performance in the company, as indicated by Silva, Correa and Gómez (2012). With this, one realizes that all management processes, in relation to organizational innovation, which can be viewed at the company (management of water, energy, waste and transport), only the transport management did not have some influence on brand analyzed. All others management forms are in the process of creating actions they can stimulate new organizational practices.

Keywords: Organizational Innovation. Sustainable Consumption. Retail.

\footnotetext{
${ }^{1}$ Artigo recebido em 24.12.2012. Revisado pelos pares em 06.05.2013. Reformulado em 25.05.2013. Aceito para publicação em 10.06.2013. Recomendado para publicação por José Ribamar Marques de Carvalho (Editor Científico). Publicado em 17.07.2013. Organização responsável UACC/UFCG.
} 


\section{INTRODUÇÃO}

A perspectiva do desenvolvimento sustentável vem sendo discutida nos últimos anos como uma visão alternativa a um conjunto de transformações que ocorrem em todo o contexto mundial. Apesar de considerada em alguns momentos como utopia, sua discussão permeia a ideia de uma preocupação a longo prazo capaz de manter atividades e disponibilidades de recursos, com o intuito de melhor trabalhar os aspectos ambientais, econômicos e sociais (KTE'PI, 2009). Nesse sentido, torna-se clara a necessidade de reestruturação no atual modelo de desenvolvimento utilizado, ao se considerar que as características individualistas estimuladas pelo capitalismo, devem ser direcionadas para uma perspectiva coletiva, com benefícios em toda a sociedade (FOLADORI, 2005).

De acordo com Peattie (2007), para que a sociedade consiga incorporar os desafios inerentes a essa forma de desenvolvimento, o principal aspecto a ser visualizado relaciona-se com a ideia de gestão, tendo em vista que os atuais padrões de produção e consumo não são sustentáveis e necessitam de melhor orientação, estando nas empresas o maior desafio de se adaptar a esse contexto. Esse fato alinhase à argumentação de que há uma indissociação e uma interdependência entre produção, mercado e consumo, percebendo-se certa dificuldade em modificar uma dessas partes sem que as demais também o sejam (TUKKER et al., 2008). Assim, para que haja a interação entre os atores no processo de continuidade das atividades humanas, surge a necessidade de discussão quanto ao consumo sustentável.

Compreendido como o padrão de consumo resultante da interação entre stakeholders em determinado contexto analisado, o consumo sustentável necessita ser trabalhado a partir de uma rede de influências de atores (MICHAELIS, 2003; SILVA, 2012). Na visão de Jackson (2007) o estudo do consumo sustentável (CS) torna-se justificável, uma vez que o mesmo procura demonstrar e compreender quais são as influências diretas e indiretas que atuam sobre o desenvolvimento sustentável. Para Michaelis (2003), ao assumir como foco as empresas, é necessário levar em consideração: (1) desenvolvimento de tecnologias e novas práticas; (2) mudança nos incentivos econômicos, já que segundo o modelo as interações sociais são modificadas em torno da empresa e (3) mudança cultural em seu contexto de influências.

Nesse contexto de mudança, entendendo a necessidade de reestruturação nas formas de produção e consumo, entende-se que o processo de inovação assume papel diferencial, já que cada vez mais as novidades no âmbito organizacional interferem no posicionamento da empresa no mercado. Pelo processo de inovação entende-se a implantação de novos produtos ou significativamente melhorado em relação às necessidades dos clientes e consumidores (OCDE, 2003), a qual assume enquanto uma de suas tipologias a inovação organizacional que está relacionada a modificações nas ações desenvolvidas pela empresa, as quais podem adaptar-se a lógica sustentável, gerando diferentes impactos empresariais. 
Considerando que a inovação pode ser contributiva diretamente para a efetivação do consumo sustentável em determinado setor econômico (Silva, Corrêa e Gómez, 2012), o objetivo do presente artigo é identificar quais e como a inovação organizacional vem sendo inserida nas práticas do Walmart Brasil, a partir da primeira dimensão do modelo de Michaelis (2003) apresentada anteriormente. Para tanto, utiliza-se o setor de supermercados como campo de estudo, buscando projetar as práticas da marca Hiper Bompreço em Recife (PE) para a compreensão do objetivo. A escolha da empresa justifica-se pelo posicionamento que vem assumindo, ao redefinir seu comportamento no mercado (GUNTHER, 2006).

Como forma de melhor compreender a proposta do artigo, o mesmo está dividido em quatro partes distintas além dessa introdutória. São apresentados num segundo momento os aspectos teóricos norteadores da pesquisa para o entendimento do fenômeno. Em seguida visualizam-se os procedimentos metodológicos. Na quarta seção são apresentados e discutidos os resultados da pesquisa, com uma caracterização macro sobre a empresa e a identificação das interações direcionadas para o consumo sustentável especificamente no que se refere à primeira dimensão do modelo estudado, por meio de possíveis inovações organizacionais. Além disso, refletindo esses resultados são apresentadas as considerações finais.

\section{DISCUSSÃO TEÓRICA}

A ideia básica do desenvolvimento sustentável está relacionada com a tarefa de harmonização de dimensões fundamentais (social, econômica e ambiental) no sentido de atender as necessidades das gerações atuais sem comprometer a satisfação das necessidades das futuras gerações (ELKINGTON, 2001; SACHS, 2007; WCDE, 1987), o que indica necessidade de envolvimento coletivo (BUARQUE, 2008). Isso se relaciona com mudanças que são observadas indicam que a atual prática de desenvolvimento visa à evidenciação do capital econômico em relação aos capitais social e natural (HAWKEN; LOVINS; LOVINS, 1999), isso ocorre tendo em vista a miopia sobre a abundância de recursos.

Nesse sentido, torna-se visível que o maior desafio, atualmente, é transformar o crescimento econômico capitalista num modelo de desenvolvimento sustentável (DS) (BROWN, 2003; CANEPA, 2007), no qual as atitudes individualistas devem ser modificadas e direcionadas para questões mais coletivas com as mudanças nos valores humanos (NORTON, 2007). Dentro dessa perspectiva, assumindo que as empresas estão inseridas em um contexto de interações sociais que surge de um envolvimento coletivo de diferentes atores (Michaelis, 2003), torna-se necessário discutir junto a esses atores aspectos referentes a uma prática mais responsável de produção e, por consequência, do consumo. Desse modo, podem-se iniciar as discussões sobre a perspectiva do consumo sustentável. 


\subsection{Consumo Sustentável}

Ao iniciar o direcionamento das ações humanas para uma perspectiva relacionada com o desenvolvimento sustentável, torna-se possível incluir a discussão do consumo com uma apreciação mais coletiva e preocupada com a continuidade da sociedade no planeta. No contexto social, a mudança nas práticas de consumo "reflete o momento cultural a qual a sociedade está inserida, perante as dinâmicas e demandas requeridas, necessitando, assim, de um direcionamento coletivo para a efetivação de um desenvolvimento emergente, o sustentável" (SILVA, 2011, p.29). Com isso, entende-se que seguindo a ideia de mudança de paradigma e considerando-a viável, estão surgindo novas preocupações do consumidor, as quais mudam o foco individualista de seu consumo para uma visão mais ampla em termos de consciência do mesmo (MICHAELIS, 2000).

Para se trabalhar com o padrão sustentável de consumo, não se devem observar apenas as ações desenvolvidas pelos consumidores, mas sim um conjunto de interações sociais que são desenvolvidas de modo tal que se consiga trabalhar a perspectiva política desenvolvida em meio as relações de consumo em determinado setor econômico. Assim, percebe-se que, para que o consumo sustentável (CS) possa ser praticado é necessária uma adequação dos padrões de consumo à nova realidade social, entendendo que a partir da redução no consumo de boa parte dos materiais, bem como de um redirecionamento das práticas desenvolvidas seu alcance se torna facilitado (JACKSON, 2004; 2007).

Para Rossetti e Giacomini Filho (2010, p.168), não se “chegou a um consenso social sobre o consumo sustentável, mas este se aloja numa nova correlação de forças amparadas em avanços consensuais favoráveis às causas ambientais, que seria uma contínua terceira via que não despreza a racionalidade em suas ponderações", mas o atual conceito, em construção, é originário de um processo consensual conduzido por organizações, pessoas e sistemas de comunicação. Isso se adéqua a ideia apresentada por Portilho e Russo (2008) que indicam a compreensão de que não apenas consumidores finais consomem, mas que práticas organizacionais também devem ser observadas nos contextos setoriais e internacionais.

De acordo com Portilho (2005), o CS surge como uma nova perspectiva em relação às estratégias públicas quanto à esfera do consumo, as novas formas de produção das empresas, bem como as mudanças comportamentais dos indivíduos no mercado. O mesmo pode ser alcançado pelo compartilhamento de responsabilidades, em meio a uma nova atuação em todas as esferas - econômicas, sociais e políticas, pressupondo a existência de consciência individual, de alinhamento organizacional aos aspectos sociais e ambientais, além da atuação de outros atores na coordenação de práticas e relações na dinâmica do consumo sustentável (SILVA, 2012). Para Jackson (2004), essa prática sustentável do consumo envolve não apenas consumir menos, mas diferente e eficientemente. 
Assim sendo, entende-se que para que seja posto em prática o consumo sustentável é necessário levar-se em consideração as relações de influência que esses stakeholders possuem sobre o consumo, no qual cada um deve assumir a identidade de seus papéis individuais, dentro da ideia de coletividade que é utilizada para o estudo da temática. Entendendo que esse é um processo cultural, complexo e capaz de auxiliar a efetivação de um novo paradigma de consumo em relação à perspectiva emergente de desenvolvimento, percebe-se que os diferentes autores que discutem consumo sustentável, direcionam seus posicionamentos para o papel dos stakeholders envolvidos nesse processo, desse modo torna-se relevante entender os compromissos e responsabilidade que os mesmos possuem nesse sentido.

Assim frente ao consumo sustentável, cada ator necessita assumir responsabilidades distintas, mas convergentes ao objetivo maior que envolve a reestruturação no paradigma de consumo utilizado. Nessa perspectiva, além das empresas que estão inseridas em diferentes estruturas e que possuem diferentes comportamentos no mercado, outros atores podem ser visualizados nesse sistema, direcionando-se para o consumo sustentável, dentre os quais se identifica: os fornecedores, os competidores, organizações do terceiro setor, as instituições financiadoras, as universidades, a mídia, o governo e os indivíduos (dentro do contexto da comunidade) (MICHAELIS, 2003; SILVA, 2012). Assume-se o foco nas empresas e em como podem contribuir para com o CS, a partir das interações com outros stakeholders.

Em geral, a comunidade empresarial tem interpretado o CS como apenas o consumo de produtos sustentáveis ou ecologicamente corretos, todavia o que se percebe é que existe uma complexidade maior que circunda a prática sustentável do consumo, por esse motivo é que se discute a ideia de interações sociais (MICHAELIS, 2003). Baseando-se nessa perspectiva, um conjunto de variáveis que estão relacionadas a essa abordagem e que facilitam a identificação prática das ações empresariais nesse sentido (SILVA, 2011). Segundo este autor devem ser analisados: Eco-eficiência, Práticas próprias de consumo, Incentivos do governo, Elos da cadeia de suprimentos, Edição de escolha, Cidadania corporativa, Marketing responsável e Diálogo com stakeholders, cada uma dessas categorias sendo desdobradas em diferentes critérios de análise a ser verificados. 


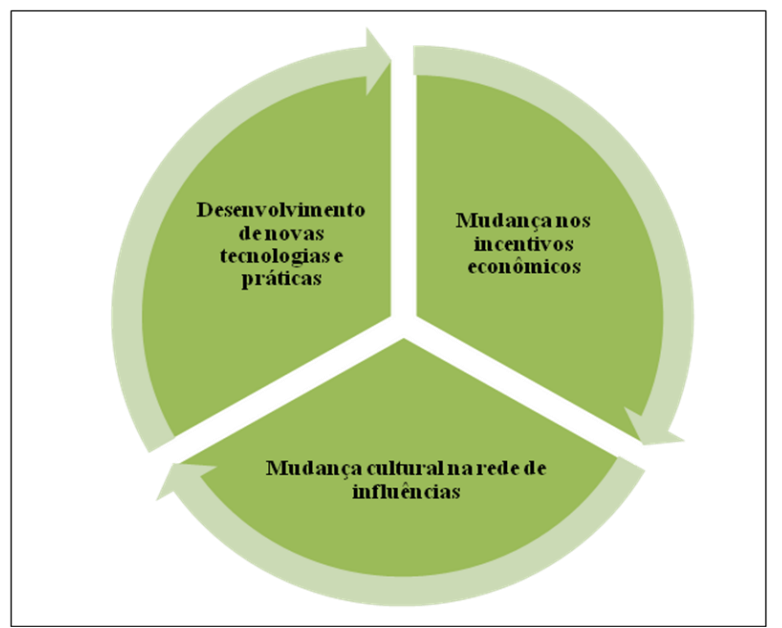

Figura 1: Representação gráfica do modelo de responsabilidade empresarial para o consumo sustentável

Fonte: Elaborado a partir de Michaelis (2003)

A partir das considerações até então apresentadas na medida em que as dimensões estão sendo observadas e praticadas pelas empresas, essas se interrelacionam e se complementam de maneira tal que muitas vezes características inerentes a uma dimensão específica do modelo podem ser observadas em práticas desenvolvidas por outra. Assim, considerando o foco na primeira dimensão do modelo, entende-se como possível sua observação a partir da discussão sobre inovação organizacional, já que com essa prática a empresa direciona-se para uma maior responsabilidade no mercado a partir da inserção de novidades e ideias para melhora de seu desempenho (SILVA; CORRÊA; GÓMEZ, 2012). Isso só é possível segundo os autores, se houver a interação com outros atores no mercado.

\subsection{Inovação Organizacional: O Desenvolvimento de Novas Tecnologias e Práticas}

Ao desempenhar o papel de fornecedor de produtos e/ou serviços com características sustentáveis, cada vez mais uma organização busca envolvimento e direcionamento para a utilização de inovações que contribuam com uma forma de atuação mais responsável no mercado (SILVA; CORRÊA; GÓMEZ, 2012). Segundo Barbieri (2007, p.99), as "inovações representam mudanças, rupturas e incertezas que serão tanto maiores quanto melhores as novidades e a abrangência dos seus impactos sobre os elementos que compõem as dimensões da sustentabilidade associada ao desenvolvimento". Essa ideia se assemelha com o conceito da OCDE (2003) que considera novidades completa ou significativamente modificadas.

Essa ideia envolve não o pensar, mas também o implementar de algo novo no mercado (SARKAR, 2008). Por ser amplo, o conceito envolve diferentes tipologias que vão desde radicais e incrementais, considerando o impacto que essa inovação tem no processo produtivo, ou mesmo, quanto a áreas específicas da empresa. Os 
tipos de inovação mais difundidos na literatura são: produto, processo, organizacional e em marketing (OCDE, 2003; SARKAR, 2008; TIDD et al., 2008), apresentando como características principais:

- Inovação em produto ou serviço: focada nas modificações potenciais dos bens e serviços, sendo considerado um aspecto agregador ou radical.

- Inovação no processo: com uma forma de produção nova ou significativamente melhorada, que envolve técnicas, equipamentos e software.

- Inovação organizacional: refere-se a modificações radicais ou incrementais nos processos de práticas de negócios na empresa, interna ou externamente, visando a melhoria no fluxo das atividades organizacionais e posicionamento de mercado.

- Inovação em marketing: impacta em todo o composto mercadológico e considera aspectos como: vendas, distribuição, embalagem, promoção e preço, para atender a diferentes necessidades dos clientes e possíveis consumidores.

Essa inovação pode estar voltada para a busca de um consumo sustentável, e ser desenvolvida em diferentes ambitos da organização, quais sejam: Estratégia, Análise do ciclo de vida do produto, Pesquisa e Desenvolvimento (P\&D), Tecnologia, Gestão de pessoas, Logística (SILVA; CORRÊA; GÓMEZ, 2013). Dentre as quais, foca-se no presente estudo o como as ações desenvolvidas quanto à tecnologia e novas praticas que sejam consideradas enquanto organizacionais, ou seja, esteja relacionada com as práticas de negocio e o comportamento que a empresa assume no mercado. Para os autores, essa reação é possível ao envolver os aspectos de mudança social e ambiental necessário para um envolvimento ativo de uma empresa nesse sentido, considera o impacto que as ações que uma empresa sobre os stakeholders que com ela interagem.

Essa nova maneira de atuação empresarial está relacionada com a atividade inovativa que envolve o direcionamento empresarial para a utilização de oportunidades junto a novas práticas de negociação que venham a surgir no mercado. Saber utilizar suas competências para obter melhor desempenho, apresenta-se como um dos aspectos mais favoráveis para a empresa, uma vez que serão vencedoras apenas aquelas que inovarem com êxito (PORTER; VAN DER LINDE, 1995). Assim, dentro da tipologia anteriormente apresentada, foca-se na inovação organizacional. Isso se relaciona com a ideia de inovação sustentável que visa proporcionar níveis de valor funcional ao reestruturar as ações do negócio (WBCSD, 2008; SILVA; CORRÊA; GÓMEZ, 2012). Em meio a essa nova forma de atuação percebe-se o surgimento da incorporação de modelos e ferramentas de gestão ambiental, bem como de aspectos que envolvem uma mudança nos valores e crenças empresariais. 
Para cada uma dessas práticas percebe-se uma aplicabilidade positiva, todavia no que se refere especificamente ao consumo sustentável, ainda existem poucos estudos quanto às práticas e tecnologias que podem ser utilizadas. Em seu trabalho, Michaelis (2003) indica a eco-eficiência como um novo paradigma tecnológico e comportamental das empresas. Tal fato é corroborado por Fuchs e Lorek (2005) e Mont e Plepys (2007) à medida que essa nova prática for incorporada aos comportamentos e atuações empresariais. Entende-se eco-eficiência como a prática empresarial que busca conciliação entre os aspectos econômicos e a redução dos impactos ambientais (ELKINGTON, 2001; MICHAELIS, 2003).

Nesse mesmo contexto, com foco em novas práticas para o consumo sustentável, emerge a ideia de certificação que se adotada pelas organizações contribui para uma produção mais sustentável e estimula os padrões de consumo nesse sentido, já que em meio às interações de mercado a incorporação de normas sociais, ambientais e de qualidade às práticas da empresa apresenta-se como necessária (SCHRADER; THOGERSEN, 2011). Para cada prática responsável da empresa, principalmente àquelas relacionadas com a questão ambiental, existe uma forma de certificação que a depender da maneira como for utilizada pode estar contribuindo com uma nova visão coletiva.

Portanto, assim que as organizações incorporam ações relacionadas com essa prática, essas estão contribuindo para o alcance do consumo sustentável. Corroborando, o WBCSD (2008) indica que a utilização da eco-eficiência demonstra que as empresas estão desenvolvendo práticas de inovação que auxiliam o alcance do CS, dentre as quais pode-se observar a reciclagem e a reutilização que são práticas internas às empresas que facilitam a redução do impacto ambiental, bem como uma melhora nos aspectos econômicos da empresa (WBCSD, 2008). Para uma contribuição ao CS necessita-se não apenas uma mudança nas tecnologias e práticas, mas uma incorporação e reestruturação de todas essas ações por parte das empresas em seu comportamento organizacional (MICHAELIS, 2003).

Nesse sentido, a reciclagem pode ser utilizada como um dos principais aspectos a serem utilizados pelas empresas para alcançar uma eco-eficiência nas ações desenvolvidas pelas mesmas no que se refere o alcance de uma produção e um consumo sustentável (MICHAELIS, 2000). É perceptível que além desse aspecto outros conseguem contribuir positivamente com o processo de mudança nos aspectos globais que direcionam os diversos atores da sociedade dentre os quais a ideia de reutilização numa perspectiva de produção limpa no qual os produtos que chegaram a um processo final podem ser reinseridos no processo produtivo (KAZAZIAN, 2005; MICHAELIS, 2000).

Diante dessa argumentação, percebe-se que além das ações voltadas para o mercado, as empresas necessitam realizar novas práticas modificando sua rotina interna, ou seja, deve haver uma preocupação com suas próprias práticas de consumo, porém com interações constantes com o mercado. Considerando aspectos relacionados ao consumo de água e energia, à gestão dos resíduos sólidos, à gestão 
dos transportes, dentre outras ações, pode-se perceber de fato uma incorporação de novas práticas e não apenas a utilização de ferramentas de gestão (MICHAELIS, 2003; MUSTER, 2010). São mudanças, que, muitas vezes, são visualizadas como mínimas, mas que de maneira ampla contribuem positivamente com a perspectiva até então discutida.

Seguindo essa perspectiva de se trabalhar com os aspectos internos, entendese que do ponto de vista dos negócios a inovação empresarial surge como fator inicial e essencial para um consumo sustentável, tendo em vista o seu caráter adaptativo às mudanças de mercado (WBCSD, 2008). As práticas iniciadas nessa dimensão do modelo de Michaelis (2003) devem estar alinhadas às demais dimensões para que a complexidade da temática possa ser observada completamente. Assim novamente ratifica-se a necessidade de interações sociais dentro de um conjunto de influências na rede de stakeholders da empresa, que de forma relacionada e complementar as demais dimensões apresentadas anteriormente precisam contribui de forma positiva ao consumo sustentável. A partir dessa visão são apresentados os procedimentos metodológicos utilizados para a operacionalização da pesquisa.

\section{PROCEDIMENTOS METODOLÓGICOS}

Com o objetivo de identificar quais e como a inovação organizacional vem sendo inserida nas práticas do Walmart Brasil, a partir da primeira dimensão do modelo de Michaelis (2003) apresentada, o desenvolvimento da pesquisa efetivou-se com uma abordagem qualitativa, na medida em que se busca entender a efetivação de uma relação (OLIVEIRA, 2005). Para tanto, a mesma pode ser considerada como exploratória por buscar o reconhecimento do contexto argumentativo-teórico e das características pertinentes ao setor e a empresa para explicar o fenômeno (CRESWELL, 2010). Para tanto, utiliza-se a estratégia de estudo de caso, já que a mesma proporciona uma visualização macro do contexto que a empresa está inserida, além de suas características singulares (GOLDENBERG, 2009).

A partir dessa perspectiva, a pesquisa focou o estado de Pernambuco, já que o mesmo é a sede da empresa na região Nordeste. Nesse contexto, a seleção da marca Hiper Bompreço é relevante pela representatividade que essa possui quanto às estratégias socioambientais do Walmart Brasil, considerando que a mesma é uma das representantes de hipermercados que integram a empresa no contexto nacional. Vale ressaltar que o trabalho é fruto de uma pesquisa maior que analisa todas as dimensões, categorias e critérios elaborados para o modelo de Michaelis (2003), todavia para questões desse artigo optou-se pelo foco na primeira dimensão que possibilita maior influência da inovação em uma empresa.

São tidos como métodos de verificação para este artigo, o levantamento bibliográfico e documental e a realização de entrevistas semiestruturadas, complementada por observação em diferentes lojas que possuem a marca. 
Participaram do processo de coleta de dados o Diretor Nacional de Comunicação, a Gerente Regional (NE) de Comunicação, que respondem diretamente sobre todas as práticas da empresa voltadas para a questão da sustentabilidade. Para a realização das análises foram utilizadas as categorias desenvolvidas por Silva (2011), as quais tiveram como foco de análise Eco-eficiência e Práticas próprias de consumo, com busca pelo destaque da inovação organizacional em suas ações estratégicas.

Definiu-se como procedimento de análise dos dados a análise de conteúdo na perspectiva de Bardin (2009) para as entrevistas realizadas, as informações contidas no website e nos documentos utilizados, bem como na análise da observação, que foi realizada tanto no momento da realização das entrevistas como nas diferentes lojas visitadas. Para a análise das categorias foram utilizados os parâmetros de análises definidos por Silva (2011) para facilitar a aplicabilidade e operacionalização da pesquisa. Com as respostas dos métodos de verificações, tornou-se possível a realização de uma triangulação de dados para efetivar a validação dos resultados encontrados (CRESWELL, 2010).

\section{RESULTADOS E DISCUSSÕES}

Os negócios do Walmart começaram a ser desenvolvidos no Brasil em 1995. Com um processo de expansão, a empresa entrou no mercado nordestino em 2004, a partir da aquisição da rede Bompreço de supermercados, agregando ao grupo mais 118 lojas e 03 centros de distribuição na região. Apesar de conhecida mundialmente, a empresa possui um destaque e uma imagem no mercado por muitos questionável a de uma empresa socioambientalmente responsável. Segundo o Diretor entrevistado, a preocupação com o problema do aquecimento global e a busca pelo atendimento da missão empresarial, que é vender por menos para as pessoas viverem melhor (Walmart Brasil, 2010a), foram estímulos para o início das práticas uma melhor qualidade de vida dos seus consumidores. Para tanto, a empresa direcionou suas atividades no sentido do chamado desenvolvimento sustentável.

De acordo com o depoimento do Diretor Nacional de Comunicação, essa nova forma de atuar da empresa 'é uma decisão corporativa global, então o programa de sustentabilidade tem metas globais, em que cada país pode adaptar algumas para sua realidade, mas a ideia de se fazer esse programa partiu desse presidente global em 2005'. Isso se apresentou como possível, com uma pesquisa sobre o impacto ambiental do Walmart sobre o meio, realizada pela Conservação Internacional e pela consultoria BluSkye (GUNTHER, 2006). Tal pesquisa mostrou que enquanto varejista a empresa não possuiria um grande impacto direto, mas que deveria reestruturar suas relações de produção e consumo.

Assim, considera-se relevante a seleção do Walmart Brasil como caso de estudo, na medida em que a empresa apresenta grande representatividade no setor, com terceiro lugar entre as empresas de supermercados do país, no ano de 2010, e um faturamento de aproximadamente $\mathrm{R} \$ 22,3$ bilhões de reais (ABRAS, 2011), bem 
como uma visível mudança no seu comportamento organizacional direcionando-se para questões socioambientais. Vale ressaltar que para a presente pesquisa, selecionou-se a marca Hiper Bompreço como o foco das análises a serem realizadas. Essa mudança indica que a empresa vem assumindo em suas diferentes lojas um novo comportamento no desenvolvimento de suas práticas, que pode facilitar a discussão da contribuição de práticas responsáveis em meio a um conjunto de interações sociais para um consumo sustentável.

\subsection{A Inserção de Novas Práticas e Tecnologias como Prática de Inovação Organizacional}

Na definição de seu modelo, Michaelis (2003) identifica, com relação ao papel que as empresas devem assumir para o consumo sustentável, como sendo a primeira dimensão a ser estudada a mudança de comportamento quanto à utilização de novas práticas empresariais e tecnológicas. Para tanto, esta dimensão pode ser analisada por meio de duas categorias teóricas, nas quais as inovações podem ser incorporadas, são elas: Eco-eficiência e Práticas próprias de consumo. Na empresa, essa dimensão pôde começar a ser discutida a partir do momento em que se preconiza a redução dos desperdícios, a ampliação da eficiência e a busca de caminhos para auxiliar as comunidades e os fornecedores (WALMART BRASIL, 2011).

Ao longo da pesquisa conseguiu-se identificar ações de inovação desenvolvidas na busca pelos estímulos a produtos mais responsáveis, no desenvolvimento de parcerias para mudança no processo de entrega do produto ao consumidor final, na utilização de um composto de marketing responsável, principalmente no mês de Julho quando ocorre a campanha Mês da Terra, além das inovações organizacionais na maneira como a empresa é vista pela sociedade. Assim percebe-se que como indicaram Silva, Corrêa e Gómez (2012) as inovações voltadas para o consumo sustentável são desenvolvidas em diferentes áreas da empresa, focando-se no caso da presente pesquisa nos aspectos de tecnologia e práticas.

\subsubsection{Eco-eficiência}

A Eco-eficiência pode ser entendida como a prática empresarial que busca conciliar o crescimento econômico e a mitigação dos impactos ambientais (FUCHS; LOREK, 2005; MICHAELIS, 2003; WBCSD, 2008). Essa conceituação indica a interação direta entre as dimensões ambiental e econômica do desenvolvimento sustentável. Para a empresa, a eco-eficiência significa "combinar aspectos ambientais, sociais e econômicos, ou seja, usar recursos naturais de forma racional e inteligente, reduzir impactos ambientais e cuidar da relação entre a empresa e as pessoas" (WALMART BRASIL, 2010b, p.35). Ou seja, está alinhado com aspectos teóricos, porém ao inserir o social do DS no entendimento do conceito pode haver prejuízo ao alcance efetivo da eco-eficiência. 
Para que essa categoria possa ser identificada numa empresa de supermercados, considera-se que devem ser praticados na mesma: a reciclagem, a reutilização, a mudança na estrutura física da loja e a certificação, de maneira tal que se consiga alinhar aspectos de gestão a uma perspectiva mais responsável. Assim sendo, para identificação da contribuição efetiva das ações empresariais para o consumo sustentável entende-se que com relação à reciclagem a existência de reaproveitamento de materiais na empresa sugere que sua prática no mercado apresenta-se como responsável para com as questões de meio ambiente. Tendo em vista esse parâmetro de análise é possível verificar no Hiper Bompreço sua aplicabilidade.

A partir do levantamento dos dados identificou-se que a empresa, de forma geral, possui uma preocupação especial com os resíduos para uma destinação correta para o mesmo, como se observa no web site; todavia, não identifica-se no Hiper Bompreço, efetivamente, o reaproveitamento de materiais em suas atividades. Tal fato não foi verificado em nenhum momento ao longo das entrevistas, dos documentos ou da observação, o que se identifica apenas é o estímulo para que os seus consumidores ampliem suas práticas de reciclagem, na medida em que são oferecidos espaços para depósito de resíduos recicláveis, dentre os quais: plásticos, vidro, papelão, pilhas e baterias de celular.

Para que esse estímulo à prática de reciclagem do consumidor ocorra, um conjunto de parceiras é realizado no sentido de melhorar o escoamento e entrega dos materiais, com a busca pela redução máxima de impacto sobre o meio ambiente. Identificam-se parcerias com as empresas Coca-cola, OnduNorte e Motorola, bem como com instituições não-governamentais, como a cooperativa Pró-Recife (WALMART BRASIL, 2010b). Essa prática é internalizada pelos funcionários, já que, durante o processo de observação na loja de Casa Forte, ao interagir com alguns desses, questionou-se sobre o destino final do material e os mesmos indicaram a efetivação do processo de reciclagem que envolve a separação, a prensa, a criação de fardos e a entrega para os destinos mais corretos.

Essa perspectiva pode ser observada como estímulo de mudança no comportamento de descarte dos consumidores e na perspectiva de impacto sobre o meio ambiente realizado por seus colaboradores, à medida que lida com esse processo interacional entre atores. Segundo Portilho (2005) essa perspectiva pode se relacionar com a ideia de consumo verde, quando o consumidor, em meio ao processo de consumo que vai desde o planejamento até o descarte, verifica o impacto ambiental de suas ações. A inserção dessa discussão demonstra um novo posicionamento interno da organização, o que estimula o processo de mudança cultural e seus reflexos sobre a sociedade.

Além dessa prática, outro processo que está alinhado com a variável de ecoeficiência é a reutilização. Avaliada a partir da ideia de que a utilização de um produto ou material mais de uma vez no sistema produtivo indica a preocupação da empresa com o impacto sobre o meio ambiente e, por conseguinte, uma maior 
responsabilidade da mesma, a variável sugere que a empresa pode melhorar sua eficiência na utilização dos recursos. Como o Walmart Brasil não possui um sistema produtivo efetivo, buscou-se identificar como ocorre o estímulo a reutilização em outras atividades da empresa.

Com isso, uma das possibilidades que poderiam ser verificadas, envolve a reutilização de água e energia solar. Levando em consideração que essas características são inerentes às lojas eco-eficientes e em Recife essas lojas não existem, a reutilização nesse sentido não é realizada. Em contrapartida, um aspecto que pode ser observado nas atividades desenvolvidas no Hiper Bompreço local refere-se à disponibilização para os consumidores de caixas de papelão para o transporte de suas mercadorias, de modo que os mesmos não utilizem mais sacolas plásticas que geram tanto impacto ao meio ambiente (WALMART BRASIL, 2011). Esse aspecto é apresentado no depoimento da Gerente Regional (NE) de comunicação da empresa, quando a mesma indica que:

Se não quiser levar sacola plástica e quiser caixa de papelão, o cliente pode pegar. Se ele não pegar e ela ficar sobrando, não tenha dúvida que ela... que alguém da loja vai pegar e dar outro destino a ela. Quando não tem... não... não tem uma reutilização imediata na loja, ela vai pra uma compactadora, [...], que fica sempre nos fundos de toda loja.

Esse trecho confirma as análises até então realizadas, já que a representante da empresa indica a não reutilização imediata de materiais na loja e explica como se dá o estímulo à reciclagem, caso o consumidor não queira utilizar a caixa de papelão ao invés das sacolas plásticas, esse material segue para o processo de reciclagem estimulado pela empresa, o que se relaciona com o que é apresentado por Kazazian (2005) sobre a reintrodução de materiais no processo produtivo, considerando as devidas proporções. Com essa visão das práticas empresariais, entende-se que a mesma necessita rever um conjunto de ações para que esteja de fato atuando na área de eco-eficiência, pois não está havendo alinhamento entre discurso e prática na empresa. Todavia, levando em consideração que os critérios de eco-eficiência para a empresa são diferentes dos definidos nesse trabalho, a mesma possui práticas que são apresentadas na seção de Práticas próprias de consumo.

Diferentemente das duas variáveis apresentadas anteriormente, percebe-se no Walmart Brasil um direcionamento positivo com relação ao desenvolvimento de aspectos de eco-eficiência voltados para a estrutura da loja. Essa variável assume a ideia de que a partir da incorporação de iniciativas empresariais voltadas para melhora em sua eficiência operacional, torna-se facilitada a definição de que a empresa possui uma prática mais responsável. Essa estrutura para o Walmart Brasil envolve um conjunto de ações a serem realizadas desde a construção até a atuação rotineira da loja. Essa ideia demonstra uma inovação física que tem total relação com o processo de eco-eficiência organizacional. Na fala do ex-presidente Hector Núñez pode-se verificar que para a empresa: 
Uma loja eco-eficiente combina economia, meio ambiente e responsabilidade social. No que diz respeito à construção, a loja minimiza os impactos ambientais lançando mão de iniciativas como o uso de energia solar para iluminação externa, coleta de água de chuva, áreas permeáveis nas superfícies, uso de tintas sem solventes e gestão eficientes de resíduos (WALMART BRASIL, 2009).

Essa ideia está relacionada com o desenvolvimento de 64 iniciativas de sustentabilidade, apresentado como principais resultados para essa nova prática da empresa a redução de $19 \%$ no consumo de energia e de $60 \%$ na emissão de gases de efeito estufa, além disso, apresenta a diminuição de $40 \%$ de consumo de água com relação às outras unidades de mesmo porte (WALMART BRASIL, 2010b). Tais resultados começaram a ser observados a partir da implantação de uma loja piloto no Rio de Janeiro em 2007. Considerada pela empresa como um laboratório para o aprendizado com relação à prática de construções sustentáveis (WALMART BRASIL, 2010c), essa primeira loja conseguiu apresentar para a empresa e para a sociedade que muitas mudanças podem ser realizadas pelo varejo de supermercados, já que seu impacto sobre o meio ambiente não é tão visível.

Apesar dessas considerações, em Recife nenhuma das lojas do Hiper Bompreço apresenta qualquer desses critérios de loja eco-eficiente tendo em vista que são lojas pré-existentes resultante do processo de aquisição do Walmart sobre a marca Bompreço no Nordeste. Esse fato foi justificado pelos entrevistados quando os mesmos indicam que práticas de eco-eficiência nas lojas são principalmente utilizadas na construção de novas lojas, isso prejudica a região, já que, segundo os mesmos, não há previsão alguma de uma nova loja ser construída na localidade. Mesmo assim, existe uma possibilidade para essas lojas, posto que, segundo o expresidente Hector Núñez, nos locais onde novas lojas não são previstas, a inserção de aspectos de eco-eficiência será realizada durante as reformas que forem realizadas, para reduzir o impacto ambiental da operação (WALMART BRASIL, 2009).

Com a realização dessas reformas a mudança na forma de atuação da empresa no mercado quanto à loja eco-eficiente vai ficar clara para o consumidor do Recife. Esse fato contribui com a ideia de que não está havendo um direcionamento da empresa para o desenvolvimento de novas práticas e tecnologias em sua área de atuação. De forma complementar à identificação dos aspectos de eco-eficiência, a certificação surge como variável que tem como parâmetro de análise que a existência de certificações na empresa indica uma contribuição para uma produção mais sustentável e novos padrões de consumo. A partir desse aspecto norteador, no Walmart Brasil não foram identificadas certificações que possuem auditoria externa.

Nesse sentido, não se percebeu na empresa a existência de ISO 14000, ISO 9000, OHSAS 18000, ou qualquer outra certificação nesse sentido. O que se percebe desde 2005, quando segundo a empresa incorporou o programa Clube dos Produtores, é a realização de auditorias anuais para certificar esses produtos. $\mathrm{Na}$ 
busca por apresentar a qualidade inerente ao produto criou-se o Selo Clube dos Produtores que recebem sinalização especial nas lojas (WALMART BRASIL, 2009, p.29). Apesar dessa indicação, a partir da observação nas lojas de Recife, não se conseguiu visualizar a certificação indicada, o que sugere um descompasso entre o discurso e prática na localidade.

Além da utilização desse selo que é apenas ilustrativo para indicação de produtos orgânicos, a certificação de órgãos públicos é solicitada como forma de certificar a procedência do produto, esse fato está alinhado com a ideia de comportamento responsável na análise da procedência do produto a ser vendido, que está alinhado com o processo de edição de escolha realizado pela empresa. Além dessas considerações, ainda no que se refere à certificação dentro da empresa, a entrevistada indicou que estão havendo estudos para o desenvolvimento de um índice que apresenta ao consumidor quais são os impactos daquele determinado produto no meio ambiente, facilitando seu processo de compra.

Esse estudo está sendo desenvolvido por uma universidade nos Estados Unidos, com o apoio do Walmart, com a busca por essa certificação de cada produto, de forma clara e precisa. Denominado Índice de Sustentabilidade, essa certificação própria, entendida como um projeto ambicioso, possui como alguns critérios: Fabricação eco-eficiente, matéria-prima reciclada, redução das emissões de gases de efeito estufa, madeira certificada, cultivo orgânico, uso eficiente da água em processo produtivo, dentre outros que estão em definição e trarão, segundo a empresa, uma nova visão para o consumidor (WALMART BRASIL, 2010b, p.21). Essa certificação é melhor definida pela Gerente Regional (NE) de comunicação:

Seria como um termômetro... sabe aquele PROCEL, que quando você compra uma geladeira ele tá lá... aí tem verde, vermelho, laranja... [...] isso foi um ganho absurdo para o consumidor, que de cara consegue enxergar o produto que ele tá levando. Ele nem entende os números que estão ali, mas não é fácil visualizar por aquela escala de cores que ela coloca em cima da geladeira? É mais ou menos isso que a gente está tentando desenvolver com a universidade. Não é fácil, porque são " $n$ " variáveis, não sei se a gente vai fazer um relógio pra colar em cima dos produtos, uma ampulheta, uma escala, mas a gente está trabalhando já faz uns dois anos, com a Universidade, pra desenvolver sim um Selo nosso, que a gente consiga aplicar nesses produtos, para o consumidor poder identificar melhor.

Esse aspecto apresenta que o Walmart vem mostrando-se pró-ativo nessa temática, buscando melhorar a apresentação dos produtos aos consumidores e assumir uma nova prática ao varejo de supermercados, já que essa certificação pode ser utilizada por todos aqueles que participam do setor. Todavia, como o Selo Clube dos Produtores é meramente ilustrativo, necessitando de selos externos para garantir a procedência do produto, e com a inexistência de certificações com auditoria externa por algum órgão, percebe-se que nesse critério, assim como nos demais sobre eco- 
eficiência, a empresa está deficiente, o que indica que a mesma não consegue nessa categoria contribuir positivamente para uma prática responsável no setor.

Essas considerações estão alinhadas às considerações apresentadas por Buenstorf e Cordes (2008) e Muster (2010) que indicam a possibilidade de incorporação e prática por parte dos colaboradores, por meio de um processo de aprendizagem e mudança nos aspectos culturais da empresa. Tal perspectiva se alinha com a discussão de Silva, Corrêa e Gómez (2012) sobre novos comportamentos internos para o consumo sustentável, o qual está condicionado a uma visão inovativa do processo. A partir das considerações, percebe-se que na empresa como um todo existe um direcionamento para o desenvolvimento de inovações organizacionais, no entanto, quando se analisa a marca Hiper Bompreço, esses aspectos são desfavoráveis a um melhor posicionamento da empresa no mercado. Desse modo, sabe-se que à medida que as mudanças vão sendo planejadas e que as ações realizadas, essas se tornam efetivas. Com isso, é necessário identificar o comportamento quanto às práticas de consumo.

\subsubsection{Práticas Próprias de Consumo}

Complementar à discussão sobre o desenvolvimento de novas práticas e tecnologias no mercado, sob o contexto de inovação organizacional, as práticas de consumo próprias de uma empresa podem ser entendidas como aquelas voltadas à preocupação com consumo de energia e água, gestão de resíduos e gestão de transportes (MICHAELIS, 2003; MUSTER, 2010). Portanto, essas variáveis que foram destacadas como essenciais para a mudança de comportamento das empresas devem ser analisadas na busca por identificar a contribuição da referida dimensão em suas atividades. Desse modo, deve-se analisar cada um desses critérios no sentido de buscar entender empiricamente como a empresa vem atuando.

No que tange o consumo de água, a partir da ideia de que a utilização de que um plano de gestão para um uso eficiente da água sugere uma melhora no consumo e na prática de sua responsabilidade, percebe-se que no Walmart Brasil esse aspecto vem sendo considerado como importante, principalmente a partir do surgimento das lojas eco-eficientes. Vale ressaltar que essa variável para a empresa é considerada como um exemplo do trabalho de eco-eficiência de suas atividades, o que está inteiramente alinhado com a seção discutida anteriormente. Com a implantação dessa gestão na empresa houve uma redução de cerca de $40 \%$ no consumo de água ao entender que:

Contribuíram para o resultado a instalação de bacias sanitárias com descargas a vácuo e de mictórios secos nos banheiros e os sistemas de captação e aproveitamento da água da chuva para limpeza das áreas externas e para o sistema de irrigação, que possui programação horária e sensores de umidade que ajudam a regular a quantidade de água necessária às plantas, evitando o desperdício (WALMART BRASIL, 2010b, p.36). 
Apesar dessas considerações, no Hiper Bompreço esse plano de gestão de água não é identificado em sua completude, tendo em vista a falta de lojas ecoeficientes na cidade e a inexistência de qualquer planejamento de reformas nas lojas já existentes. Segundo a Gerente Regional (NE) de Comunicação da empresa, algumas das iniciativas que envolvem a gestão dos recursos hídricos utilizados pela empresa facilitam a busca pela redução de água nas lojas em Recife de maneira tal que aos poucos a mesma vai se direcionando para uma preocupação gradativa com o desperdício desse recurso natural, como a instalação de bacias sanitárias com descargas de duplo acionamento.

Em contrapartida ao processo de inserção do plano de água não ser totalmente efetivo na localidade estudada, os aspectos relacionados à variável energia podem ser melhor observados. Para a análise da prática de consumo de energia entende-se que a utilização de um plano de gestão para um uso eficiente de energia sugere uma melhora no consumo e na prática de sua responsabilidade da empresa. Com essa visão, de forma geral nas lojas eco-eficientes, a redução no consumo de energia apresenta-se como significativa, mesmo assumindo apenas 19\% de redução. Esse número é importante porque o varejo trabalha com o destaque de produtos em seu salão de vendas e possui muitos expositores verticais que necessitam da energia.

Com uma mudança gradativa das atividades na gestão da energia trabalha tanto com a ideia de modificação nos recursos utilizados para as lojas, como também na utilização de outras fontes de energia, como a solar, essa prática começa a ser agregada às atividades da empresa. Mesmo possuindo essa visão de que a mudança dos equipamentos pode contribuir positivamente com a atuação do Walmart Brasil, identificou-se que no Hiper Bompreço, em Recife, as lojas apresentam apenas algumas dessas iniciativas, já que ainda não entraram no processo de reforma. De acordo com a Gerente Regional (NE) de Comunicação:

Ao passar dos anos, os equipamentos vão sendo depreciados e precisando de uma troca, [...] aí que entra a substituição por esses equipamentos novos, mas enquanto o balcão refrigerado do Hiper Caxangá tá bom e tá atendendo, dificilmente vai se trocar por outro LED ou com Sensor.

Desse modo, percebe-se que o plano de gestão de energia em Recife apresentase em desenvolvimento, e que, com ao longo dos anos, com as possíveis reformas que aconteçam, o mesmo pode vir a ser integrado às atividades do Hiper Bompreço. Com essas afirmações, percebe-se que até o presente momento, no que se refere às práticas próprias de consumo, voltadas para a água e a energia, pode-se verificar que na marca estudada os referidos critérios estão sendo praticados aos poucos, mas não alinhados à perspectiva de eco-eficiência. Assim, entende-se que a possibilidade de atuação efetiva desses critérios na referida marca envolve claramente a necessidade de novas construções sustentáveis ou reformas nas existentes. 
Outra variável a ser considerada na análise das práticas de consumo do Hiper Bompreço refere-se à gestão de resíduos. Para tanto, entende-se que a utilização de um plano de gestão de resíduos na empresa, facilita o menor desperdício de materiais na mesma, ou seja, uma nova forma de atuação. Identificou-se que a gestão de resíduos tem focado dentre outros aspectos "o processo de planejamento desde a construção e a inauguração até a operação da loja" (WALMART BRASIL, 2009, p.71). Todavia, como não estão surgindo novas lojas eco-eficientes na cidade, então essa consideração não foi identificada na marca estudada. Essa variável está alinhada diretamente com as de eco-eficiência reciclagem e reutilização e sugere a preocupação com o descarte correto dos resíduos.

Para tanto, no Walmart Brasil identifica-se que existe um programa de gerenciamento de resíduos efetivo chamado Impacto Zero, que visa facilitar a incorporação do pensamento por parte de seus colaboradores (funcionários, estagiários e prestadores de serviço) de sua responsabilidade enquanto integrante da empresa e cidadão na sociedade que deve estar preocupado com o resultado de suas ações. O referido projeto tem obtido, segundo os Relatórios de Sustentabilidade da empresa, bons resultados de maneira tal que vem conseguindo trabalhar com a redução no desperdício de materiais e melhorar o comportamento de seus integrantes com relação a essa atividade.

Esse plano de gerenciamento facilita uma melhor atuação da empresa com relação aos impactos sobre o meio ambiente. No Hiper Bompreço de Recife identifica-se a busca pelo atendimento de sua proposta, o que indicaria um direcionamento positivo da empresa nesse sentido, todavia não foram identificados aspectos claros durante as entrevistas e observações sobre a efetividade do projeto na marca. Caso se consiga alinhar a variável com a reciclagem e a reutilização, o Walmart Brasil em suas diferentes marcas cada vez mais vai se apresentar eficiente no mercado facilitando uma mudança em seu comportamento. A partir dessas considerações foram analisados os principais aspectos voltados para as práticas de consumo interna da empresa, no entanto, necessita-se observar como isso ocorre externamente.

Nesse sentido, a última variável dessa categoria a ser analisada envolve a gestão de transportes. Entende-se que a partir a gestão do impacto que os transportes da empresa impõem sobre o meio ambiente e sua efetiva modificação, mais responsável a prática da empresa. A preocupação com essa prática de consumo leva o Walmart Brasil a observar seu impacto ambiental relacionado, por exemplo, com a emissão de gases de efeito estufa sobre a atmosfera. Considerada pela empresa como uma dos principais pilares de atuação, voltado para a preocupação com o clima, a redução desses gases apresenta-se como intensiva por parte da empresa (WALMART BRASIL, 2010c). A partir de todas as ações que já foram desenvolvidas, segundo dados, cerca de $60 \%$ de emissões foram controladas.

Isso envolve, além de outros aspectos, a gestão dos transportes da empresa. Como o Walmart Brasil é um intermediário do canal de distribuição que não realiza 
entregas diretamente ao consumidor final, sua contribuição para esse critério analisado foi observado de forma indireta. Desse modo, com relação a essa variável, a empresa desenvolve anualmente um fórum de discussão com diferentes atores: fornecedores, pesquisadores ou órgãos governamentais com um objetivo único que é identificar soluções para a redução do impacto dos transportes, evento esse denominado Fórum Walmart Brasil de Sustentabilidade em Transportes (WALMART BRASIL, 2010c).

Segundo a empresa, em parceria com fornecedores, a mesma começou a testar alternativas para aumentar a eficiência dos veículos, como o uso de defletores e redução de viagens de caminhões vazios (WALMART BRASIL, 2010c, p.40), além disso, tem buscado diminuir o impacto do uso de combustíveis fósseis ao estimular o uso do biocombustível. A partir de todas essas ações que são desenvolvidas pela empresa em âmbito nacional, percebe-se que a mesma pode estar contribuindo para com um novo padrão de consumo em algumas regiões, todavia, no que tange, a marca Hiper Bompreço em Recife não se pode afirmar a existência de ações que contribuam para o consumo sustentável no varejo local.

Como todas essas variáveis estão relacionadas à categoria eco-eficiência, percebe-se que a marca Hiper Bompreço está aquém do necessário para contribuir com a mudança nos padrões de consumo do setor. Assim, a empresa deve começar a aplicar mais iniciativas de eco-eficiência e reestruturar suas práticas próprias de consumo, com a inserção de maiores inovações, de maneira tal que se torne efetiva e perceptível o desenvolvimento de novas práticas e tecnologias na localidade estudada, modificando o seu comportamento no mercado. Assim, como indica por Silva, Corrêa e Gómez (2012) a gestão de diferentes áreas de uma empresa pode ser desenvolvida no sentido de melhorara sua atuação, tornando-se facilitada uma maior contribuição das inovações para o consumo sustentável.

\section{CONSIDERAÇÕES FINAIS}

Cada vez mais para uma adequação melhor ao que vem sendo almejado pelo mercado, as organizações estão necessitando desenvolver práticas inovativas que impactam em seu desempenho no mercado e modificam seu posicionamento no mesmo. Considerando a ideia do desenvolvimento sustentável, quanto mais às inovações se tornarem sustentáveis e estimularem uma maior responsabilidade das organizações no mercado, melhor para a construção de padrões de produção e consumo sustentáveis. Desse modo, tais inovações podem assumir atuação em áreas exclusivas da empresa, ou focar diferentes formas de envolvimento organizacional, desde o planejamento estratégico até o processo logístico.

A partir de todas as considerações até então realizadas, percebe-se o atendimento do objetivo de pesquisa, à medida que se apresentou quais e como as inovações organizacionais poderiam contribuir para o consumo sustentável no setor. No âmbito do Walmart Brasil, em contexto nacional, diferentes práticas de inovação 
puderam ser observadas principalmente a partir da construção de um planejamento estruturado e relacionamento com diferentes atores para melhor adequação de seus negócios ao mercado. Isso está alinhado com os pilares estratégicos por ela definidos, já que existe convergência de práticas. Apesar disso, no que se refere à marca Hiper Bompreço isso foi pouco visível no contexto local e cultural visualizado.

Como se observou ao longo da pesquisa, aquelas poucas inovações visualizadas em Recife-PE foram implementadas sob o contexto de inovações incrementais, com pequenas ações resultantes do que se impõe nacionalmente, ou seja, nenhuma mudança radical foi identificada. Isso se apresenta como contraditório para a organização, já que nas outras lojas na região Nordeste e no Brasil as inovações são observadas, com isso necessita de melhor definição das estratégias da empresa para a localidade. Todo esse pensamento pode estar alinhado à busca pelo desenvolvimento sustentável.

Toma-se como limite da pesquisa a utilização de apenas uma dimensão do modelo, já que se buscou o foco nas inovações organizacionais, e como limitações a quantidade de entrevistas realizadas, pois mesmo representativas e principais poderiam ter sido inseridos trechos de conversas com funcionários, por exemplo. Recomenda-se para futuras pesquisas a ampliação das marcas da empresa analisada, bem como a aplicação da pesquisa em outros setores econômicos, o que pode trazer novas contribuições. Diante dessa ideia, percebe-se que o presente estudo contribui para com a visão de inovações para o consumo sustentável e ratifica a necessidade de novas pesquisas nesse campo de atuação.

\section{REFERÊNCIAS}

ABRAS - Associação Brasileira de Supermercados. Ranking Abras. 2011. Disponível em: <http://www.abras.com.br/economia-e-pesquisa/ranking-abras/historico/> Acesso: mai. 2011.

BARBIERI, J. C. Organizações inovadoras sustentáveis. In: BARBIERI, J. C; SIMANTOB, M. Organizações inovadoras sustentáveis: uma reflexão sobre o futuro das organizações. São Paulo: Atlas, 2007.

BARDIN, L. Análise de Conteúdo. 4ª ed. Lisboa: Edições 70, 2009.

BROWN, L. Eco-economia. EPI - Earth Policy Institute / UMA - Universidade Livre da Mata Atlântica. 2003. Disponível em: $<$ http://www.ethos.org.br/_Uniethos/Documents/livro.pdf $>$. Acesso em: nov. 2010.

BUARQUE, S. C. Construindo o desenvolvimento local sustentável. 4. ed. Rio de Janeiro: Garamond, 2008. 
BUENSTFORT, G.; CORDES, C. Can sustainable consumption be learned? A model of cultural evolution. Ecological Economics. P.646-657. 2008.

CANEPA, C. Cidades sustentáveis: o município como lócus da sustentabilidade. São Paulo: RCS Editora, 2007.

CRESWELL, J. W. Projeto de pesquisa: métodos qualitativo, quantitativo e misto. 3. ed. Porto Alegre: Artmed/Bookman, 2010.

ELKINGTON, J. Canibais com garfo e faca. São Paulo: Makroon Books, 2001.

FOLADORI, G. Por uma sustentabilidad alternativa. Uruguai: Colección Cabichui, 2005.

FUCHS, D. A.; LOREK, S. Sustainable consumption governance: A history of promises and failures. Journal of Consumer Policy. V.28, p.261-288. 2005.

GOLDENBERG, M. A arte de pesquisar: como fazer pesquisa qualitativa em ciências sociais. Rio de Janeiro: Record, 2009.

GUNTHER, M. The Green Machine. 2006. Fortune Magazine. Disponível em: <http://money.cnn.com/magazines/fortune/fortune_archive/2006/08/07/8382593/>. Acesso em: jul. 2011.

HAWKEN, P.; LOVINS, A. e LOVINS, H. Natural Capitalism: creating the next industrial revolution. Little Brown - USA, 1999. Disponível em: http://www.natcap.org/. Acesso em: jul. 2010.

JACKSON, T. Negotiating Sustainable Consumption: A review of the consumption debate and its policy implications. Energy \& Environment. V. 15, n.6. p.1027-1051. 2004.

Sustainable Consumption. In: ATKINSON, Giles; DIETZ, S.; NEUMAYER, E. (editors). Handbook of Sustainable Development. Edward Elgar Publishing, 2007.

KAZAZIAN, T. Haverá a idade das coisas leves: design e desenvolvimento sustentável. SP: SENAC SP, 2005.

KTE'PI, B. Sustainable Development. Encyclopedia of Business In Today's World. SAGE Publications. 2009.

MICHAELIS, L. Sustainable consumption and production. In: DODDS, F.; MIDDLETON, T. Earth Summit 2002: A new deal. Earthscan Publications Ltd. 2000. 

v.11. 2003.

The role of business in sustainable consumption. Journal of Cleaner Production,

MONT, O.; PLEPYS, A. Sustainable consumption progress: should we be proud or alarmed? Journal Cleaner Production. V.16, p.531-537. 2007.

MUSTER, V. Companies promoting sustainable consumption of employees. Journal of consumer policy. Springer Science. 2010.

NORTON, B. G. Ethics and sustainable development: an adaptive approach to environmental choice. In: ATKINSON, Giles; DIETZ, Simon; NEUMAYER, Eric (editors). Handbook of Sustainable Development. Edward Elgar Publishing, 2007.

OECD. Manual de Oslo: diretrizes para coleta e interpretação de dados sobre inovação. Terceira Edição. Tradução FINEP, 2003.

OLIVEIRA, M. M. Como fazer pesquisa qualitativa. Recife: Ed. Bagaço, 2005.

PEATTIE, K. Toward sustainable organizations for the 21st century. 21st Century Management: A Reference Handbook. SAGE Publications. 2007.

PORTER, M. E.; VAN DER LINDE, C. Green and competitive: Ending the stalemate. Harvard Business Review, September - October, 1995, pp. 120-134.

PORTILHO, M. F. F. Sustentabilidade Ambiental, consumo e cidadania. São Paulo: Cortez, 2005.

PORTILHO, M. F. F.; RUSSO, F. F. Processo Marrakech - O consumo sustentável visto pelos organismos internacionais. In Anais... IV Encontro Nacional da Associação Nacional de Pós-Graduação e Pesquisa em Ambiente e Sociedade. Brasília: ANPPAS, 2008.

ROSSETTI, R.; GIACOMINI FILHO, G. Comunicação, consenso social e consumo sustentável. Comunicação, mídia e consumo. Vol. 7, (18). p. 153-169. 2010.

SACHS, I. Rumo à ecossocioeconomia: Teoria e prática do desenvolvimento. São Paulo: Cortez, 2007.

SARKAR, S. O empreendedor inovador: faça diferente e conquiste o seu espaço no mercado. Rio de Janeiro: Elsevier, 2008. 
SCHRADER, U.; THOGERSEN, J. Putting sustainable consumption into practice. Journal of consumer policy. Springer Science. 2011.

SILVA, M. E. A contribuição de práticas empresariais responsáveis para o consumo sustentável no varejo de supermercados: O caso Walmart Brasil. 137p. Dissertação (Mestrado em Administração) - Programa de Pós-Graduação em Administração (PROPAD). Universidade Federal de Pernambuco, Recife: 2011.

Consumo Sustentável: A Articulação de um constructo sob a perspectiva do desenvolvimento sustentável. Revista Eletrônica de Ciências Administrativas (RECADM). Vol. 11, (2). 2012.

SILVA, M. E.; CORRÊA, A. P. M.; GÓMEZ, C. R. P. Inovando para o Consumo Sustentável: o desafio na construção de um novo paradigma organizacional. Revista de Negócios (Online), v. 17, n. 2, 2012.

TIDD, J.; BESSANT, J.; PAVITT, K. Gestão da Inovação. 3. ed. Porto Alegre: Bookman, 2008.

TUKKER, A.; EMMERT, S.; CHARTER, M.; VEZZOLI, C.; STO, E.; ANDERSEN, M. M.; GEERKEN, T.; TISCHNER, U.; LAHLOU, S. Fostering change of sustainable consumption and production: an evidence based view. Journal of cleaner production, v. 16. 2008.

WALMART BRASIL. Institucional Walmart. 2010a. Disponível em: $<$ http://www.walmartbrasil.com.br/institucional/nomundo.aspx>. Acesso em: dez. 2011.

Relatório de sustentabilidade 2009 (Exercício 2008). 2009. Disponível em: <http://www.walmartsustentabilidade.com.br/_pdf/relatorios/walmart-relatorio-desustentabilidade-2009.pdf $>$ Acesso em: dez. 2011.

Relatório de sustentabilidade 2010 (Exercício 2009). 2010b. Disponível em: $<$ http://www.walmartsustentabilidade.com.br/_pdf/relatorios/walmart-relatorio-desustentabilidade-2010.pdf> Acesso em: dez. 2011.

Relatório de sustentabilidade 2011 (Exercício 2010). 2011. Disponível em:

$<$ http://www.walmartsustentabilidade.com.br/relatorio-

online/downloads/Walmart_RA10_pt.

pdf> Acesso em: dez. 2011. 
Sustentabilidade no Walmart Brasil. 2010c. Disponível em: <http://www.walmartsustentabilidade.com.br/home/>. Acesso em: ago. 2011.

WBCSD - World Business Council for Sustainable Development. Sustainable Consumption: Facts e Tends - From a business perspective. 2008. Disponível em: $<$ http://www.wbcsd.org/DocRoot/I9Xwhv7X5V8cDIHbHC3G/WBCSD_Sustainable_ Consumption_web.pdf $>$. Acesso em: mai. 2012.

WCED - World Commission on Environment and Development. Report Our common future. Genebra, 1987. Disponível em: <http://www.un-documents.net/wcedocf.htm.>. Em: 2010. 